\title{
Polarimetric C-Band SAR Observations of Sea Ice in the Greenland Sea
}

\section{Thomsen, Bjørn Bavnehøj; Nghiem, S.V.; Kwok, R.}

\section{Published in:}

Geoscience and Remote Sensing Symposium Proceedings, 1998. IGARSS '98. 1998 IEEE International

Link to article, DOI:

10.1109/IGARSS.1998.702259

Publication date:

1998

Document Version

Publisher's PDF, also known as Version of record

Link back to DTU Orbit

Citation (APA):

Thomsen, B. B., Nghiem, S. V., \& Kwok, R. (1998). Polarimetric C-Band SAR Observations of Sea Ice in the Greenland Sea. In Geoscience and Remote Sensing Symposium Proceedings, 1998. IGARSS '98. 1998 IEEE International (Vol. 5, pp. 2502-2504). IEEE. https://doi.org/10.1109/IGARSS.1998.702259

\section{General rights}

Copyright and moral rights for the publications made accessible in the public portal are retained by the authors and/or other copyright owners and it is a condition of accessing publications that users recognise and abide by the legal requirements associated with these rights.

- Users may download and print one copy of any publication from the public portal for the purpose of private study or research.

- You may not further distribute the material or use it for any profit-making activity or commercial gain

- You may freely distribute the URL identifying the publication in the public portal 


\title{
Polarimetric C-band SAR Observations of Sea Ice in the Greenland Sea
}

\author{
B. B. Thomsen ${ }^{1}$ \\ S. V. Nghiem ${ }^{2}$ \\ R. Kwok ${ }^{2}$ \\ ${ }^{1}$ Danish Center for Remote Sensing, Technical University of Denmark \\ Anker Engelundsvej 1, Building 348, DK-2800 Lyngby, Denmark \\ Tel: +45 4588 1444, Fax: +45 4593 1634, E-mail: bbt@emi.dtu.dk \\ ${ }^{2}$ Jet Propulsion Laboratory, MS 300-235, California Institute of Technology \\ 4800 Oak Grove Drive, Pasadena, CA 91109, USA
}

\begin{abstract}
The fully polarimetric EMISAR acquired C-band radar signatures of sea ice in the Greenland Sea during a campaign in March 1995. We present maps of polarimetric signatures over an area containing various kinds of ice and discuss the use of polarimetric SAR for identification of ice types and their geophysical characteristics.
\end{abstract}

\section{INTRODUCTION}

Synthetic Aperture Radar (SAR) has been used to map sea ice for operational applications and climatic studies. Current and future satellite SAR systems such as ERS, RADARSAT, and ENVISAT operate at different polarizations. Hence, the SAR data cannot be directly compared without understanding the effect of polarizational dependence. Also different meteorological conditions can have a significant impact on measured backscatter levels of sea ice and open water, that often cause ambiguity in identifying the correct ice type. Polarimetric SAR can improve ice analyses due to the increased amount of independent information. The Danish airborne system EMISAR has, as the only system so far, acquired C-band polarimetric SAR data of sea ice in the Greenland Sea. The observations obtained with EMISAR have high spatial and radiometric resolutions and a low noise equivalent backscatter. The high resolution allows small areas of ice to be analyzed and limits the mixing of different ice types. The low noise allows more ice types with low backscatter to be imaged.

\section{DATA ACQUISITION}

Fully polarimetric SAR data were obtained with the EMISAR system. The scattering matrix data in 2 meter resolution were converted to covariance matrix data in a resolution of $25 \mathrm{~m}$ to reduce the speckle noise. We

The study was carried out as a part of the research programme at Danish Center for Remote Sensing, which is established and funded by the Danish National Research Foundation, and as a part of the Commission of the European Communities ESOP project through contract MAS2-CT93-0057. Development of the EMISAR was sponsored by the Thomas B. Thrige Foundation, the Danish Technical Research Council (STVF), the Royal Danish Air Force (RDAF), the Technical University of Denmark, and the Joint Research Centre (JRC). The research by the Jet Propulsion Laboratory was carried out under a contract with the National Aeronautic and Space Administration. analyzed the data with respect of the reciprocity principle, and found very good agreement between the observed HV-VH correlation coefficient and the noise statistics of the system, i.e. backscatter equivalent noise level ( -35 $\mathrm{dB})$ and crosstalk $(-30 \mathrm{~dB})$. We verify the reciprocity between $\mathrm{HV}$ and $\mathrm{VH}$ to within $0.3 \mathrm{~dB}$ in power and 1 degree in phase. The cross-polarized scattering matrix elements have been averaged coherently to further reduce the noise level to $-38 \mathrm{~dB}$. The radiometric resolution is better than $0.2 \mathrm{~dB}$. The system frequency is $5.3 \mathrm{GHz}$, and the incidence angles are in the range from 38 to 61 degrees.

The complex backscatter coefficient is defined as [1]

$$
\sigma_{\mu \tau \nu \kappa}^{0}=\frac{4 \pi}{A}<S_{\mu \tau} S_{\nu \kappa}^{*}>
$$

where $A$ is the illuminated area, $S_{r t}$ is the scattering matrix element at receive polarization $r$ and transmit polarization $t$. We denote the co-polarized backscatter coefficients in a more compact notation as

$$
\begin{aligned}
& \sigma_{h h}^{0}=\sigma_{h h h h}^{0} \\
& \sigma_{v v}^{0}=\sigma_{v v v v}^{0}
\end{aligned}
$$

The coherent average of the cross-polarized scattering matrix elements is equivalent to

$$
\sigma_{x p}^{0}=\frac{1}{4}\left(\sigma_{h v h v}^{0}+\sigma_{h v v h}^{0}+\sigma_{v h h v}^{0}+\sigma_{v h v h}^{0}\right)
$$

We have analyzed polarimetric parameters: copolarized ratio, cross-polarized ratio, co-polarized correlation coefficient, co-polarized phase difference, and symmetry parameter $\delta_{1}$. They are defined as follows:

$$
\begin{aligned}
r_{c p} & =\sigma_{v v}^{0} / \sigma_{h h}^{0} \\
r_{x p} & =\sigma_{x p}^{0} / \sigma_{h h}^{0} \\
\rho_{h h v v} & =\sigma_{h h v v}^{0} / \sqrt{\sigma_{h h}^{0} \sigma_{v v}^{0}} \\
\varphi_{h h v v} & =\tan ^{-1}\left(\frac{\operatorname{Im}\left(\sigma_{h h v v}^{0}\right)}{\operatorname{Re}\left(\sigma_{h h v v}^{0}\right)}\right) \\
\delta_{1} & =\frac{r_{x p}}{\frac{1}{2}\left(1-\left|\rho_{h h v v}\right|\right)}
\end{aligned}
$$

The symmetry parameter was shown by [2] to be related to the structure of the scattering medium. 
In addition to the EMISAR acquisitions, an under flight was carried out in low altitude for ice reconnaissance. The observations, including aerial photos and recorded video sequences, were within few hours from the SAR observations.

\section{ICE CONDITIONS}

We have analyzed ERS-1 SAR together with NOAA AVHRR imagery obtained over the region within few minutes from the EMISAR acquisition. The AVHRR data shows partly cloud cover of the region. The large scale conditions seems to be in agreement with previous observations of the Marginal Ice Zone in the Greenland Sea.

The EMISAR covered an area of well mixed and relatively large floes. Leads can be observed in EMISAR, ERS, and AVHRR images.

Meteorological data were obtained from stations on the Greenland East coast in the region of the EMISAR acquisitions. At Daneborg (200 km North to the acquisition) the air temperature was reported to be lower than $-15^{\circ} \mathrm{C}$ in 8 days prior to the acquisition with typical diurnal fluctuations of $5^{\circ} \mathrm{C}$. The measured air temperature at Daneborg 1 hour before acquisition was $-22^{\circ} \mathrm{C}$, and the wind was $3 \mathrm{~m} / \mathrm{s}$ from North. Other Meteorological stations in the vicinity reveals similar observations of low temperatures and low wind conditions, with the latest storm being more than one week prior to the acquisitions.

Aerial photos and recorded video sequences were evaluated to give a general indication of ice type and thickness. Three distinct types of ice could be identified: nilas, grey ice, and white ice. We did not observe any significant snow cover on nilas or grey ice.

\section{OBSERVATIONS}

Figure 1 shows the polarimetric signatures obtained from covariance matrix data in $25 \mathrm{~m}$ resolution. The maps cover a $8 \mathrm{~km}$ by $6 \mathrm{~km}$ subset within the incidence angle range $45^{\circ}$ to $56^{\circ}$, with near range to the left side. A 1$2 \mathrm{~km}$ wide freezing lead is seen between the thicker ice. The thin ice sheet in the lead is further broken across the lead leaving a narrow opening of water or very thin ice approximately $100 \mathrm{~m}$ wide. Observations from the under flight verify the presence of the lead partly covered with thin ice.

The backscatter level $\left(\sigma_{h h}^{0}\right)$ is substantially lower in the lead area compared to the surrounding ice, but large fluctuations occur within both the thick ice and the lead area.

A better separation is obtained from the co-polarized ratio $\left(\mathrm{r}_{c p}\right)$, where two distinct types of thin ice are observed. These can easily be distinguished from each other and from the thick ice. The narrow opening has the same $\mathrm{r}_{c p}$ as the one type of thin ice. The two areas of thin ice with different levels of $r_{c p}$ are not separable in the visual images.

The cross-polarized ratio $\left(r_{x p}\right)$ is very low for some areas that has been identified as grey ice (including the very dark floe in the middle left side of the lead). For some areas, including the narrow opening, the ratio is very high. However, due to very low levels of $\sigma_{h v}^{0}$, these areas might appear with an artificially high cross-polarized ratio.
The magnitude of the co-polarized correlation coefficient $\left(\left|\rho_{h h v v}\right|\right)$ is generally high, except for smaller parts of the thick ice. Low $\left|\rho_{h h v v}\right|$ can be caused by a mixture of different scattering mechanisms within the resolution cells. There is no clear separation in the $\left|\rho_{h h v v}\right|$ levels between the different ice types, although the variation is much higher in the thick ice.

The co-polarized phase $\left(\varphi_{h h v v}\right)$ shows significantly large differences between the ice in the lead and the thick ice, but it also shows a clear separation between the ice in the lead area and the narrow opening.

The $\delta_{1}$ symmetry parameter is found to be close to unity for most regions. However very high $\delta_{1}$ values are observed for the narrow opening in the lead, which indicate that scatterers have some preferential structures. On the border between the opening and the ice in the lead, very low $\delta_{1}$ values occurs. Same low values are also found as long lines in the upper part of the lead.

\section{DISCUSSION}

We have presented a set of polarimetric signatures and showed how they reveal different features of sea ice. No single polarimetric parameter can discriminate well between all ice types. However, by combining various polarimetric information, we find that a much better discrimination can be obtained.

For discriminating water and thick ice, we find $r_{c p}$ to be very useful. However for discriminating water and thin ice, we found both $\varphi_{h h v v}$ and $\delta_{1}$ to be very useful. Thin ice and thick ice can be separated using $\mathrm{r}_{c p}$ or $\varphi_{h h v v}$.

The delta symmetry parameter $\delta_{1}$ is expected to be larger than unity for vertical oriented scatterers and below unity for horizontal scatterers, and the observations shows how distinct types of ice and water eventually can be separated.

A certain type of ice is observed in $\delta_{1}$, and is barely observed in other parameters. By relating the observation to symmetrical properties and taking the meteorological conditions into consideration, we find this type is likely to be new forming congelation ice with vertical oriented scatterers.

The studies shows the usefulness of several polarimetric parameters, of which the co-polarized ratio in particular should be addressed attention, since future satellite systems, like ENVISAT, might be able to obtain this parameter.

By comparing the data from the under flight with the SAR acquisition, we observed divergence of the lead area. The thicker floes was not observed to undergo any deformation. Hence the physical properties of especially the thin ice might have changed. This fact makes it difficult to assign different regions to the correct ice type at this level.

In our further studies, polarimetric observations will be studied with physical models of sea ice types found in the region. Typical parameters of marginal ice zone measurements will be applied to the models. The modeling results help improve our understanding of the polarimetric signatures of ice in the marginal ice zone. 


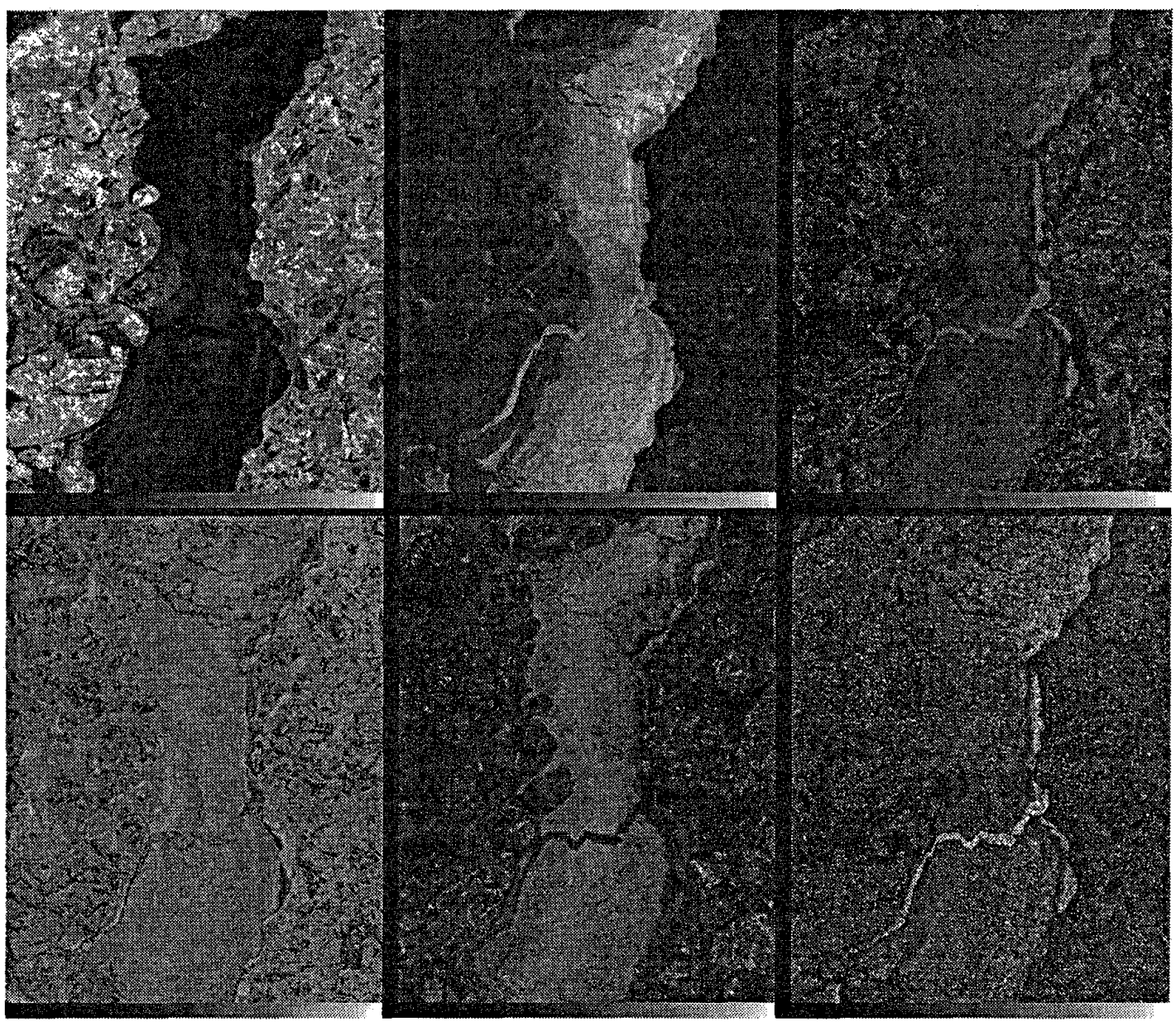

Figure 1. EMISAR polarimetric C-band signature maps of sea ice observed in the Greenland Sea, March 1995. All signatures map are scaled linear within specified ranges (from upper left to right): $\sigma_{h h}^{0}[-30:-10 \mathrm{~dB}], \mathbf{r}_{c p}[-5: 10 \mathrm{~dB}], \mathbf{r}_{x p}[-15: 0 \mathrm{~dB}],\left|\rho_{h h v v}\right|[0: 1]$, $\varphi_{h h v v}\left[-30: 90^{\circ}\right]$, and $\delta_{1}[0: 2]$.

\section{CONCLUSIONS}

The polarimetric SAR study shows that: (1) copolarization phase difference can be used for separating water and different ranges of thin ice, and (2) different types of symmetries in the scattering mechanisms can be detected and used to separate in particular frazil and congelation ice in newly formed leads and open water. We also find that (3) co-polarization ratio is useful for separating multiyear ice from rough thin ice and open water. We relate the observed phase difference of thin ice to its anisotropic behavior. Furthermore, different values of $\delta_{1}$ result from different symmetrical properties related to the growth structure of ice or the directional structure of water waves. These properties help to eliminate some of the ambiguities in SAR data analyses of sea ice.

\section{ACKNOWLEDGMENTS}

We thank the Danish Meteorological Institute and the Royal Danish Air Force for providing aircraft facilities for the campaign. We also thank staff at Danish Center for Remote Sensing for their efforts in the acquisition and processing of data.

\section{REFERENCES}

[1] S. V. Nghiem, S. H. Yueh, R. Kwok, and F. K. Li, "Symmetry properties in polarimetric remote sensing", Radio Sci., vol. 27, no. 5, pp.693-711, September-October, 1992.

[2] S. V. Nghiem, S. H. Yueh, R. Kwok, and D. T. Nguyen, "Polarimetric remote sensing of geophysical structures", Radio Sci., vol. 28, no. 6, pp.1111-1130, NovemberDecember, 1993. 